\title{
Collagen Sources and Areas of Use
}

\author{
Melat Cherim \\ Umf Carol Davila Bucharest, Faculty of Pharmacy, Str. Traian Vuia No. 6, Sector 2, Bucharest, Romania
}

Alef Mustafa

Umf Carol Davila Bucharest, Faculty of Pharmacy, Str. Traian Vuia No. 6, Sector 2, Bucharest, Romania

Emin Cadar

Umf Carol Davila Bucharest, Faculty of Pharmacy, Str. Traian Vuia No. 6, Sector 2, Bucharest, Romania

Naliana Lupașcu

Umf Carol Davila Bucharest, Faculty of Pharmacy, Str. Traian Vuia No. 6, Sector 2, Bucharest, Romania

Stelian Paris

Ovidius University of Constanta, Faculty of Pharmacy, Campus Corp B, University Alley No. 1, Constanta, Romania

Rodica Sirbu

Corresponding Author, Sirbu_27@Yahoo.Com

Ovidius University of Constanta, Faculty of Pharmacy, Campus Corp B, University Alley No.1, Constanta, Romania

\section{Abstract}

Fibrillar collagen type I undenatured represent the major structural component of all organs and connective tissues, which due to low antigenicity and outstanding biocompatibility the possibility of controlling the time of biodegradation by crosslinking, the ease of forming composites with other natural polymers and synthetic, represents one of the most used natural biomaterials . Collagen biomaterials are successfully used in gene therapy for artificial implants. They are used as medical devices, scaffolds for tissue regeneration, supports for drug release. Collagen can be extracted from various sources considering that it is one of the most abundant proteins on earth. It can be extracted from almost every living animal, even including alligators and kangaroos. Nonetheless, common sources of collagen for tissue engineering applications include bovine skin and tendons, porcine skin and rat tail among others. Marine life forms are also a considerable source of collagen, which can be extracted from sponges, fish and jellyfish. These collagens are widely used in the industry, but less for research and clinical usage. All these collagen sources are worth investigating considering that collagen properties differ from one animal to another. Collagen can also be used in biomedical applications as a decellularized ECM serving as a scaffolding material for tissue regeneration. Although extractible from many different sources, the diversity of acellular. Due to these features and the possibility to be isolated in pure collagen, they are essential in areas such as medicine, cosmetics, food and pharmaceutical applications.

Keywords: collagen type I, biomaterials, natural polymers, collagen sources. 


\section{INTRODUCTION}

The interest for collagen covers a historical long duration starting with leather processing, culinary uses and ending with pharmaceutical and biomedical applications. Behind the interest for collagen were the specific features and potential applications of collagen determining also the abundant data on this subject in scientific literature [1]. The benefits of using collagen in the biomedical and pharmacy area are coming from the fact that collagen is part of the architecture and functionality of the organism. On the human lifespan, collagen decreases quantitatively, with important consequences on the functioning of organs. It is estimated that after the age of 25 , the decrease is $1.5 \%$ of the normal rate, which is not compensated by biosynthesis. Thus, collagen supplementation through diet or other ways is physiologically relevant for all organs and functions on whose regeneration to contribute [1].

About the diversity of data, selective approaches on issues have been adopted related to characterization, obtaining and exploitation of collagen in the biomedical-pharmaceutical field, which require conservation of certain biologically active features of native collagen. The presence of collagen in almost all organs and tissues, it's structural and biochemical peculiarities and role in human sanogenesis justify the effort of scientists in finding collagen implications in normal or pathological processes of the human body.

\section{The Collagen Molecule}

\subsection{Distribution, biosynthesis and molecular structure}

The presence of collagen in all connective tissue makes it one the most studied biomolecules of the extracellular matrix (ECM). This fibrous protein species is the major component of skin and bone and represents approximately $25 \%$ of the total dry weight of mammals [1]. To this day, 29 distinct collagen types have been characterized and all display a typical triple helix structure. Collagen types I, II, III, V and XI are known to form collagen fibers. Collagen molecules are comprised of three a chains that assemble together due to their molecular structure. Every a chain is composed of more than a thousand amino acids based on the sequence -Gly-X-Y-. The presence of glycine is essential at every third amino acid position in order to allow for a tight packaging of the three a chains in the tropocollagen molecule and the $X$ and $Y$ positions are mostly filled by proline and 4-hydroxyproline [2, 3]

Composition of Fish Waste The composition of the fish varies according to the type of species, sex, age, nutritional status, time of year and health. Most of the fish contains $15-30 \%$ protein, $0-25 \%$ fat and $50-80 \%$ moisture $[4,5]$. Suvanich et al. [6] reported that the composition of catfish, cod, flounder, mackerel and salmon variedaccording to the species (Table 1, Fig. 1). Mackerel had the highest fat content $(11.7 \%)$ and cod had the lowest $(0.1 \%)$. Salmon had the highest protein content (23.5\%) and flounder had the lowest (14\%). The moisture content of the five fishes varied between 69 and $84.6 \%$ but the ash content of all species was similar. The fish proteins are found in all parts of the fish. There are three types of proteins in fish: structural proteins, sacroplasmic proteins and connective tissue proteins. The fish proteins can be extracted by chemical and enzymatic process.

\section{RESEARCH METHODS}

\section{SOURCES OF RAW MATERIALS. TREATMENTS TO OBTAIN EXTRACTS OF NATURAL COLLAGEN}

The main sorce of fibrillar collagen type I is animal skin. Traditionally, collagen was isolated from the skin of animals such as cattle and swine. To these sources were added lately marine organisms, generally fish, witch results in marine collagen. Even if it doesn't differe significantly from land collagen, it has certain commercial and technological advantages.

It is a known fact that in some countries, swine and cattle products are prohibited or difficult to access, so marine collagen represents an important sorce. Collagen is a typical animal derived. We mention this becouse in the commercialization of natural products a new collagen is used, and that is the vegetable collagen. Such products are actually mixtures, blends of collagen with different ingredients of vegetable origin or products based on soybean oil, which does not stand for the name of collagen. 
Table I Collagen types, forms and distribution.

\begin{tabular}{|l|l|l|}
\hline Type & Molecular Formula & Tissue \\
\hline I & {$\left[\alpha_{1}(\mathrm{I})\right]_{2}\left[\alpha_{2}(\mathrm{I})\right]$} & Skin, Bones, Tendon \\
\hline II & {$\left[\alpha_{1}(\mathrm{II})\right]_{3}$} & Tendons, cartilages \\
\hline III & {$\left[\alpha_{1}(\mathrm{III})\right]_{3}$} & Skin, liver \\
\hline IV & {$\left[\alpha_{1}(\mathrm{IV})\right]_{2}\left[\alpha_{2}(\mathrm{IV})\right]$} & Base membranes \\
\hline V & {$\left[\alpha_{1}(\mathrm{~V})\right]_{2}\left[\alpha_{2}(\mathrm{~V}]\right.$} & Amniotic membrane \\
\hline VI & {$\left[\alpha_{1}(\mathrm{VI})\right]\left[\alpha_{2}(\mathrm{VI})\right]\left[\alpha_{3}(\mathrm{VI})\right]$} & Cornea \\
\hline VII & {$\left[\alpha_{2}(\mathrm{VII})\right]_{3}$} & Sustaining fibres \\
\hline VIII & {$\left[\alpha_{1}(\mathrm{VIII})\right]_{2}\left[\alpha_{2}(\mathrm{VIII})\right]$} & Endothelial cells \\
\hline IX & {$\left[\alpha_{1}(\mathrm{IX})\right]\left[\alpha_{2}(\mathrm{IX})\right]\left[\alpha_{3}(\mathrm{IX})\right]$} & Cartilages \\
\hline $\mathrm{X}$ & {$\left[\alpha_{1}(\mathrm{X})\right]_{3}$} & Bone-cartilages transition tissue \\
\hline $\mathrm{XI}$ & {$\left[\alpha_{1}(\mathrm{XI})\right]\left[\alpha_{2}(\mathrm{XI})\right]\left[\alpha_{3}(\mathrm{XI})\right]$} & Cartilages \\
\hline $\mathrm{XII}$ & {$\left[\alpha_{1}(\mathrm{XII})\right]_{3}$} & Skin bones \\
\hline XIII & {$\left[\alpha_{1}(\mathrm{XIII})\right]$} & Muscles, cartilages \\
\hline $\mathrm{XIV}$ & {$\left[\alpha_{1}(\mathrm{XIV})\right]$} & Skin, cartilages \\
\hline $\mathrm{XV}$ & {$\left[\alpha_{1}(\mathrm{XV})\right]$} & Uterus, kidney \\
\hline
\end{tabular}

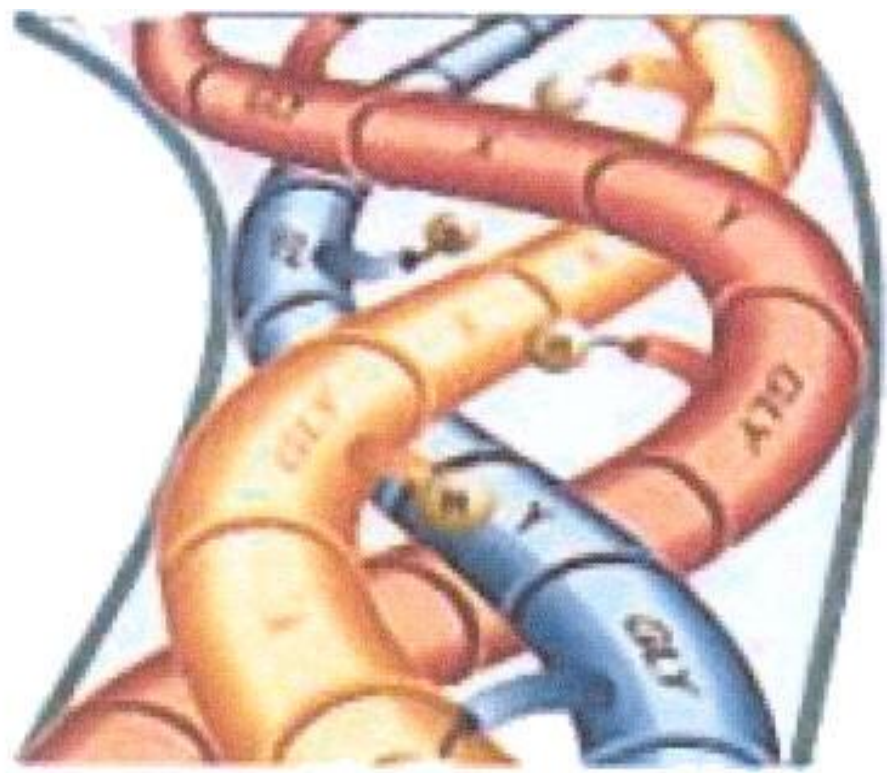

Figure 1. Schematization of a collagen a chain triple helix segment.

\section{The fish proteins can be extracted by chemical and enzymatic process.}

In the chemical method, salts $(\mathrm{NaCl}$ and $\mathrm{LiCl})$ and solvents (isopropanol and aezotropic isopropanol) are used, whereas during the enzymatic extraction, enzymes (alcalase, neutrase, protex, protemax and flavorzyme) are used to extract 
proteins from fish. These fish proteins can be used as a functional ingredient in many food items because of their properties (water holding capacity, oil absorption, gelling activity, foaming capacity and emulsifying properties). They can also be used as milk replacers, bakery substitutes, soups and infant formulas. The amino acids are the building blocks of protein. There are 16-18 amino acids present in fish proteins.

The amino acids can be produced from fish protein by enzymatic or chemical processes. The enzymatic hydrolysis involves the use of direct protein substrates and enzymes such as alcalase, neutrase, carboxypeptidase, chymotrypsin, pepsin and trypsin.

In the chemical hydrolysis process, acid or alkali is used for the breakdown of protein to extract amino acids. The main disadvantage of this method is the complete destruction of tryptophan and cysteine and partial destruction of tyrosine, serine and threonine. The amino acids present in the fish can be utilized in animal feed in the form of fishmeal and sauce or can be used in the production of various pharmaceuticals.

\section{Collagen and gelatin}

The fish skin waste is a good source for collagen and gelatin which are currently used in food, cosmetic and biomedical industries. Collagen and gelatin are two different forms of same macromolecule in which gelatin is a partially hydrolysed form of collagen. The collagen and gelatin are two unique and more significant forms of proteins in comparison to that of fish muscle proteins. The significance lies upon the amino acid content; more than $80 \%$ are non-polar amino acids such as glycine, alanine, valine and proline [7]. Heat denaturation of collagen easily converts it into gelatin. The collagen and gelatin extracted from bovine sources pose the risk of mad cow disease or bovine spongiform encephalopathy (BSE), whereas the collagen and gelatin extracted from fish skin eliminates these risks of BSE. The gelatin extracted enzymatically from fish skin has better biological activities as antioxidants and antihypertensive agents. The gelatin has a unique repeating sequence of glycine-proline-alanine in their structure compared to the peptides derived from fish muscle protein and it is the main reason behind the antioxidative propertyof gelatin $[8,9]$.

\section{Chemical extraction of fish protein}

The most common extraction method used for the fish proteins is the solvent extraction method. The standard protocol for the solvent extraction of proteins reported by Sikorski and Naczk [10]. The whole fish is first ground and the protein is extracted using isopropanol. After grinding, the supernatant is collected and extracted three times. The first extraction is carried out at $20-30^{\circ} \mathrm{C}$ for $50 \mathrm{~min}$ in isopropanol. The second extraction is carried out at $75^{\circ} \mathrm{C}$ for 90 min with isopropanol. The third extraction is carried out at $75^{\circ} \mathrm{C}$ for $70 \mathrm{~min}$ with azeotropic isopropanol. The final supernatant fraction is collected, dried, milled and screened to separate out bone particles. Hermansson et al. [11] reported that the fish protein concentrate can also be produced at a temperature of $50^{\circ} \mathrm{C}$ but it will have lower emulsifying properties and poor solubility. The disadvantages of this method are poor functionality, off-flavours, high cost of production and traces of the solvent in the final product, making it commercially unsuccessful. Another chemical method for the production of fish protein concentrate and gelatin was reported by Arnesen and Gildberg [12].

$2000 \mathrm{~g}$ of the Atlantic cod are added to $2000 \mathrm{~mL}$ of water and the $\mathrm{pH}$ is adjusted to 11 with $62 \mathrm{~mL}$ of $3 \mathrm{M} \mathrm{NaOH}$. The first extraction is carried out for $15 \mathrm{~min}$ and the sample is centrifuge is then suspended in $2000 \mathrm{~mL}$ and the pH is adjusted to 11 with $3 \mathrm{M} \mathrm{NaOH}(15 \mathrm{~mL})$. The second extraction is carried out for $60 \mathrm{~min}$ and the sample is then centrifuged. The pellet is again suspended in $2000 \mathrm{~mL}$ of water and the $\mathrm{pH}$ is adjusted to 2 with $3 \mathrm{M} \mathrm{HCl}(145 \mathrm{~mL})$. The third extraction is carried out for $15 \mathrm{~min}$ and centrifuged. The supernatants from the three extracts are pooled together and the $\mathrm{pH}$ was adjusted to 7 with $3 \mathrm{M} \mathrm{NaOH}$.

\section{RESULTS OF COLLAGEN APPLICATIONS IN BIOMEDICAL AND PHARMACEUTICAL INDUSTRIES}

The collagen itself is considered a drug/active ingredient, being used - in various forms - as a hemostatic and dressing treatment of various types of injuries. Regenerative-inductive qualities determine the use of collagen as a substitute of skin of bone.The positive effects of collagen on tissue regeneration and its iteraction with the cells are the main cause of interest 
of the local treatmant of the affecte tissue or the formation of new tissue, e.g., bone skin or nerves, using the scaffolds based of collagen. However the, natural protein, collagen alone can not cure an infected tissue alone, becouse the more there is the more bacteria can use it as a substrate.[13]

Due to the excellent biocompatibility and biodergradability, well-defined structure, biological characteristics and how it interacts with tissues, collagen is one of the most used biomaterials. Extracted as a aqueous solution or gel, collagen fibrillar type I, can be molded into various forms such as medical devices, artificial implants, supports for the disposal of drugs and skeletons(scaffolds) for regenaration of the tissue, with an important role in present medical practice.

In severe infections of the wound, systemic administration of drugs can lead to insufficient drug concentrations or drug side effects and/or systemic toxicity. This deficiency was solved successfully in local applications of drugs, thus developing delivery systems that have underlying collagen and as an antibiotic drug/antiseptic for infection control.[5]

Although intensely investigated worldwide, only a few controlled drug delivery systems (DDS) based on collagen were clinically tested and placed on the medical market. Their development is focusing on the so-called "smart systems" that are able to keep or dispose of controlled amount of medication. Moreover, with these developments there will be a better understanding of the great benefits derived from the local disposal of medicines, some of the new systems, collagen-drug, can replace standard systemic treament with antibiotics.[3]

Recent research have as subject the development of drugs delivery systems, growth factor, proteins, hormones, enzymes etc.. Collagen, used as an adequate support for drugs, offers the advantage of being a natural biomaterial with astrigent properties and wound healing. [14].

\section{Utilization of amino acids}

Amino acids are the building blocks of proteins. They have wide nutritional value, taste, medicinal action and chemical properties. All amino acids are sold in different quantities each year. They are used as food additives, in pharmaceutical applications, feed and food supplements. The amino acids such as arginine, glycine ,glutamate and histidine are used in protein pharmaceuticals as an excipient for drug development is shown. The largest consumer of amino acids is the food flavoring industry which uses monosodium glutamate, alanine, aspartate and arginine to improve the flavour of food. The second largest consumer of amino acids is the animal feed industry which uses lysine, methionine, threonine, tryptophan and others to improve the nutritional quality of animal feed. The amino acids can also used in various pharmaceutical applications such as protein purification and formulations and production of antibiotics such as jadomycin [15]. The total amino acid market in 1996 was estimated to be $\$ 4.5$ billion. The market value of amino acids has drastically increased since 1996 [16]. Fermentation products in 2004 were estimated to be $\$ 14.1$ billion and $\$ 17.8$ billion and amino acids were the second most important category after antibiotics in 2009 [17].

\section{Current applications worth mentioning:}

In medical field: treatment for hypertension, urinary incontinence and pain associated with osteoarthritis, inhibition of agiogenic diseases, such as complications of diabetes, obesity and arthritis.[4]. Fish collagen is a product with a real potential to become a key element in the development of artificial bones and therapies made for this purpose [18]. In ophthalmology, researchers are trying to implant biodegradable collagen in gaucoma surgerys [19].

Pharmaceutical: they are used as excipients for various forms of drugs administration, vector systems for the controlled release of active substances emulsions, pastes, eye washes and various containers [13].

In the cosmetic field: base for emulsions and cosmetic creams, complex systems of chemical peels, used as a gel, cream, serum or injections, collagen improves the suppleness and elasticity of the skin, repairing the damage caused by age and exposure to UV radiation.

Marine collagen cannot be injected at this time, so its effect is limited to the creams and masks in which is used. It may be also administered orally. [20]. In its hydrolyzed form, collagen is used as a nutritional adjunct in beverages, pasta and bakery products. [13] 


\section{CONCLUSIONS}

- $\quad$ This scientific work achieves its informative purpose in providing inside the narrated documents with useful data for researches in the field.

- $\quad$ The presented information, open the possibility of valorizations of black sea domestic resources associated with technological options and drug delivery systems with particular originality potential applications based on a specific area.

- Towards this diversity of data, we adopted a carefull and selective approach on issues related to characterization, abtaining and exploitation of collagen in the biomedical-pharmaceutical fields, that require the use of certain feutures and attributes preserving biologically native active collagen.

\section{REFERENCES}

[1] Marine Collagen www. super smart.eu.

[2] M. CHVAPIL, Reconstituted collagen,in „Biology of collagen”, ed .A. Viidik si aj .Vuust, Academic Press, London , 1980

[3] K.P. Rao si T. Josep,Collagen graft copolymers and their biomedical applications, in „, Collagen Biotechnology”, ed. .M.E. Nimni, CRC Press, Boca Raton, 1988

[4] Murray J, Burt JR , The composition of fish. Ministry of Technology. Torry Research Station. Torry Advisory Note No. 38, 2001

[5] Ghaedian R, Coupland JN, Decker EA, McClemets JD Ultrasonic determination of fish composition. Journal of Food Engineering 35: 323-337, 1998

[6] Suvanich V, Ghaedian R, Chanamai R, Decker EAEA, McClements DJ Prediction of proximate fish composition from ultrasonic properties: catfish, cod, flounder, mackerel and salmon. Journal of Food Science 63: 966-968, 2006

[7] Byun HG, Kim SK) Purification and characterization of angiotensin I converting enzyme (ACE) inhibitory peptides from Allaska Pollack (Theragrachalcogramma) skin. Process Biochemistry 36: 1155-1162, 2001

[8] Kim SK, Mendis E Bioactive compounds from marine processing byproducts - A review. Food Research International 39: 383-393, 2005

[9] Byun HG, Kim YT, Park PJ, Lin X, Kim SK Chitooligosaccharides as a novel ß-secretase inhibitor. Carbohydrate Polymers 61: 198-202, 2005

[10] Sikorski ZE, Naczk M Modification of technological properties of fish protein concentrates. Crit Rev Food Sci Nutr 14: 201-230, 1981

[11] Hermansson AM, Sivik B, Skjoldebrand C Factors affecting solubility, foaming and swelling of fish protein concentrate. Lebensmittel-Wissenschaft and Technologie 4: 201-204, 1971

[12] Arnesen JA, Gildberg A Extraction of muscle proteins and gelatin from cod head. Process Biochemistry 41: $697-700,2006$

[13] G. Goissis, L, Piccirli, J.C. Goes, A,M.De Guzzi Plepis and D.K., Das -GUPTA, Anionic collagen; polymer composites with improved dielectric and rheological properties, Artificial Organs, 22, 203-209, 1998

[14] Hudson, T.W.; Zawko, S.; Deister, C.; Lundy, S.; Hu, C.Y.; Lee, K.; Schmidt, C.E. Optimized acellular nerve graft is immunologically tolerated and supports regeneration. Tissue Eng., 10, 1641-1651, 2004

[15] Arakawa T, Tsumoto K, Kita Y, Chang B, Ejima D Biotechnology applications of amino acids in protein purification and formulations. Amino Acids 33: 587-605, 2007 
[16] Ikeda M Amino acid production processes. In: Scheper T, Faurie R, and Thommel J (eds) Advances in biochemical engineering/biotechnology. Springer, Berlin Heidelberg New York, 2003

[17] Leuchtenberger W, Huthmacher K, Drauz K Biotechnological production of amino acids and derivatives: current status and prospects. Appl Microbiol Biotechnol 69: 1-8. 143. Shahidi F (2003) Extraction and Measurement of Total Lipids. Current Protocols in Food Analytical Chemistry. 144, USA 79: 1-35, 2005

[18] http/: www.acvaristica.info/acvaristica-articole

[19] http:// WWW.OFTAMEDICA.RO

[20] http://www.desprespa.ro/SPA/Ingrediente-produse-spa/Tratamente 